\title{
Evaluación físico-química, microbiológica y sensorial del queso fresco utilizando ficina como biocatalizador
}

\section{Assessment physical-chemical, microbiological and sensory of fresh cheese using ficin as a biocatalyst}

Josselyn Gabriela Bermeo Berrones. ${ }^{1}$, Iván Patricio Salgado Tello. ${ }^{2}$, Cesar Iván Flores Mancheno.

${ }^{3}$ \& Tatiana Elizabeth Sánchez Herrera. ${ }^{4}$

\begin{abstract}
.
DOI: $\underline{\text { https://doi.org/10.33262/concienciadigital.v3i2.1.1238 }}$

In the present investigation, it was proposed to carry out a comparative analysis of cheese made with the proteolytic enzyme ficin, which is derived from the latex of Ficus carica known as (fig). since its proteolytic activity is manifested by denaturing its substrate proteins by breaking the disulfide bonds generated by sulforated amino acids identified as cysteine since it belongs to the group of thiol proteases and is very similar to papain that is extracted from papaya latex, and commercial cheese, for which the T-student test was used, with a unit size of 4 liters with 5 repetitions where in the physical-chemical analysis similar values were obtained in $\%$ of humidity, Aw, $\mathrm{pH}$ except for protein since there is a difference of $8.86 \%$; While the enzymatic activity presents values of $14.87 \mathrm{U} / \mathrm{mg}$ of protein with a time of 58 seconds corresponding to an effective enzymatic speed and clotting time. No presence of pathogenic microorganisms was reported in the microbiological analysis. In the sensory analysis, the paired preference test was used where $100 \%$ of tasters preferred commercial fresh cheese. Enzymatic purification is recommended to improve protein content.
\end{abstract}

Keywords: Comparative Analysis, Proteolytic Enzyme, Ficin, Enzymatic Purificación

\footnotetext{
${ }^{1}$ Profesional independiente, josslyn@yahoo.es

${ }^{2}$ Escuela Superior Politécnica de Chimborazo, Facultad de Ciencias Pecuarias, ivan.salgado@espoch.edu.ec

${ }^{3}$ Escuela Superior Politécnica de Chimborazo, Facultad de Ciencias Pecuarias, ifloresm1@yahoo.es

${ }^{4}$ Escuela superior politécnica de Chimborazo, Facultad de Ciencias Pecuarias, tsanchez@espoch.edu.ec
} 


\section{Resumen.}

En la presente investigación se propuso efectuar un análisis comparativo realizado al queso elaborado con la enzima proteolítica ficina la cual es proveniente del látex de Ficus carica conocida como (higuera). ya que su actividad proteolítica se manifiesta al desnaturalizar sus proteínas sustrato mediante la ruptura de los enlaces disulfuro generados por aminoácidos sulfurados identificada como cisteína ya que pertenece al grupo de las tiol proteasas y es muy similar a la papaína que se extrae del látex de papaya, y al queso comercial, para lo cual se utilizó la prueba T-student, con tamaño de unidad de 4 litros con 5 repeticiones donde en el análisis físico-químico se obtuvo valores similares en \% de humedad, Aw, $\mathrm{pH}$ a excepción de la proteína ya que existe una diferencia de $8,86 \%$; Mientras que la actividad enzimática presenta valores de 14,87 U/mg de proteína con un tiempo de 58 segundos correspondientes a una eficaz velocidad enzimática y tiempo de coagulación. No se reportó presencia de microorganismos patógenos en el análisis microbiológico. En el análisis sensorial se utilizó la prueba de preferencia pareada donde el $100 \%$ de catadores prefirió el queso fresco comercial. Se recomienda realizar una purificación enzimática para mejorar el contenido de proteína.

Palabras claves: Análisis Comparativo, Enzima Proteolítica, Ficina, Purificación Enzimática

\section{Introducción.}

Mucho antes que los microorganismos, los vegetales han sido objeto de investigaciones con el fin de aislar sus enzimas. Efectivamente el jugo de muchas especies puede dar origen a la coagulación de la leche, pero las enzimas que se extraen tienen una actividad proteolítica bastante intensa en relación a su actividad coagulante. (Bermeo, 2019, citado en Maigua, A, 2017: p.32). Es decir, presenta componentes activos con capacidad coagulante y pueden producir la desestabilización de las micelas de caseína y la formación del gel láctico o cuajada en la fabricación quesera. Los extractos vegetales se han utilizado desde tiempos antiguos como coagulantes para la elaboración de queso, ya que la primera referencia escrita data del año 50 a.C. y hace referencia a la coagulación con cardo, semillas de cártamo (Bermeo, 2019, citado en Víctor, 2015, p.23).

Las enzimas vegetales son muy eficaces como catalizadores, son capaces de aumentar la velocidad de las reacciones químicas mucho más rápido que cualquier catalizador artificial conocido, cabe recalcar que son altamente específicas, es decir que cada una de ellas induce la transformación de un solo tipo de sustancia y son muy activas a temperatura y presión atmosférica. (Bermeo, 2019, citado en Acosta, R, 2011, p.1).

Las enzimas proteolíticas son ubicuas y capaces de llevar a cabo reacciones muy específicas. Esta última característica las ha posicionado como enzimas muy atractivas para diferentes industrias. Las enzimas hidrolíticas representan el 75\%, del mercado mundial de enzimas industriales, de los cuales el 60\% corresponde a las proteasas (Bermeo, 2019, citado en Juca, D, 2015: pp. 84-86). 
Las proteinasas vegetales encargadas de la coagulación comparten un segmento extra de alrededor de 100 residuos, específico de las plantas. Este segmento tiene una secuencia de aminoácidos que las hace distintas a las proteinasas aspárticas de origen animal o microbiano (Bermeo, 2019, citado en Acosta, R, 2011: p. 17). También según diversos autores dicen que una de las principales características que poseen las enzimas provenientes del reino vegetal es la ausencia de toxinas que podrían afectar la salud de los consumidores. (Bermeo, 2019, citado en Pezo, k, 2018: p.34-35) Tienen aplicaciones en campos industriales, siendo la industria de detergentes y alimenticia sus principales mercados. A su vez, considerando las tendencias actuales de implementar tecnologías ambientalmente amigables, la utilización de enzimas proteolíticas se ha extendido a otras industrias. Algunos procesos químicos que usualmente se realizaban en condiciones de temperatura y $\mathrm{pH}$ extremos, o altas presiones, pueden realizarse por reacciones enzimáticas en condiciones más moderadas. (Bermeo, 2019, citado en Juca, D, 2015: pp. 84-86).

Las aplicaciones son muy diversas y se puede pensar que serían similares a las de la papaína, proveniente del látex de la papaya y otras proteasas entre las cuales se pueden enumerar las siguientes (Bermeo, 2019, citado en Pilar, et al., 2007: p 20)

- Industria cervecera.

- Industria de la carne.

- Industria del cuero.

- Industria textil.

- Industria medicinal.

- Industria de alimentos (jugos).

- Industria de alimentos (dietéticos infantiles).

- Industria alimenticia (lácteos).

Las enzimas proteolíticas presente en el látex de la higuera, han sido extensamente estudiadas y son las denominadas "ficinas", comparando su actividad con la bromelina y la papaína. Sin embargo, en el fruto de la higuera, el higo, no se han reportado estudios sobre la actividad proteolítica y coagulante que estos presentan (Bermeo, 2019, citado en Juca, D, 2015: p.19).

La ficina es una cisteína proteasa proveniente del látex de las plantas del género Ficus, su actividad proteolítica se manifiesta al desnaturalizar sus proteínas sustrato mediante la ruptura de los enlaces disulfuro generados por aminoácidos sulfurados. (Bermeo, 2019, citado en Carrera, J, 2003, p.15); Presenta hidrólisis preferencial por los aminoácidos aromáticos. El pH óptimo varía con el sustrato y se encuentra en el rango de 5 a 8 . La temperatura óptima está alrededor de $60{ }^{\circ} \mathrm{C}$, inactivándose completamente a los $80^{\circ} \mathrm{C}$. (Bermeo, 2019, citado en Vega, K, 2017, p.22)

En la industria alimenticia la principal aplicación de las proteasas es en la elaboración de quesos, en donde su función es la coagulación de las proteínas lácteas, específicamente hidrolizando el 
enlace Phe106-Met106 de la k-caseína para dar lugar a para-k-caseína y otros macro péptidos (Bermeo, 2019, citado en Gallardo, et al., 2008: pp. 1-3)

La leche puede ser coagulada mediante numerosas enzimas proteolíticas que provienen de variadas fuentes, tales como diferentes especies de animales, proteinasas microbianas y proteínas extraídas de frutas como la frutas, como la papaya, piña, higo, cardo. Según diversos autores dicen que una de las principales características que poseen las enzimas provenientes del reino vegetal es la ausencia de toxinas que podrían afectar la salud de los consumidores. (Bermeo, 2019, citado en Pezo, k, 2018: p.34-35)

\section{La coagulación por acción enzimática ocurre en dos fases sucesivas, siendo éstas:}

Fase enzimática o "reacción primaria", en el curso de la cual la enzima ataca a la caseína y solubiliza una pequeña parte. La reacción no necesita la presencia de ion calcio.

Fase de coagulación o "fase secundaria", involucra a la mayor parte de las sustancias que proceden de la reacción química. Esta reacción precisa la presencia de calcio iónico.

Además, el mismo autor señala que es necesario añadir dos fases más para obtener el conjunto de fenómenos consecutivos a la acción enzimática. (Bermeo, 2019, citado en abril, A, 2013: pp. 2022). Debido a que hay un gran desconocimiento en temas de la actividad enzimática de las enzimas proteolíticas ya sea por falta de recursos humanos, materiales para el desarrollo de proyectos en este tema, esta investigación brindará resultados estadísticos que pueden servir para la pequeña y media industria ofreciendo como alternativa el uso de la enzima proteolítica ficina en sus procesos de producción para la obtención de quesos. (Bermeo, 2019, citado en Víctor, 2015, p.23)

Esta investigación conlleva a la utilización de mecanismos en la producción de muchos alimentos y productos especialmente como es el queso con la ayuda de las enzimas proteolíticas de origen vegetal, debido a que su función es transformar sustancias para dar productos finales.

Por lo expuesto anteriormente se planteó el siguiente objetivo:

Analizar las características físico-químicas, microbiológicas y sensoriales de una muestra de queso fresco con la mejor actividad enzimática.

\section{Metodología}

El desarrollo de la siguiente investigación se realizó en la Facultad de Ciencias Pecuarias y en la Facultad de Ciencias de la Escuela Superior Politécnica de Chimborazo, ubicada en la Panamericana Sur km $1 \frac{1}{2}$ en la ciudad de Riobamba, provincia de Chimborazo-Ecuador.

Los análisis se realizaron en los laboratorios de Bromatología y Procesos Industriales, encontrándose a una altitud de $2740 \mathrm{msnm}, 78^{\circ} 4^{\prime}$ ' de Longitud Oeste y $1^{\circ} 38^{\prime}$ de Latitud Sur. En la investigación se realizó la elaboración de queso fresco y comparación con un cuajo vegetal

\section{Unidades Experimentales}

En la elaboración del producto final que es el queso fresco se utilizó 4 litros de leche por cada repetición, con cinco repeticiones cada tratamiento. 
ISSN: 2600-5859

Vol. 3, N², p. 231-249, abril - junio, 2020

Materiales, equipos e instalaciones

Para la realización de la siguiente investigación será necesario la disponibilidad de los siguientes materiales, equipos e instalaciones

Tabla No1. Materiales, equipos e instalaciones

\begin{tabular}{|c|c|c|c|c|c|}
\hline Materiales & Materia prima & $\begin{array}{l}\text { Materiales } \\
\text { de oficina }\end{array}$ & Equipos & Laboratorio & Reactivos \\
\hline $\begin{array}{l}\text { Recipientes de } \\
\text { plástico. } \\
\text { Cuchillos. } \\
\text { Bisturí. } \\
\text { Pipeta. } \\
\text { Vasos de } \\
\text { precipitación. } \\
\text { Frascos de vidrio. } \\
\text { Espátula. } \\
\text { Matraces } \\
\text { Erlenmeyer. } \\
\text { Probeta. } \\
\text { Crisoles de } \\
\text { porcelana } \\
\text { Pinzas } \\
\text { Varilla de vidrio } \\
\text { Vasos de } \\
\text { precipitación } \\
\text { Papel parafina } \\
\text { Mandil } \\
\text { Cofia } \\
\text { Guantes }\end{array}$ & $\begin{array}{l}\text { Materia prima } \\
\text { para la } \\
\text { obtención de } \\
\text { las enzimas } \\
\text { (higo). } \\
\text { Materia prima } \\
\text { para la } \\
\text { elaboración de } \\
\text { queso (leche } \\
\text { vaca) }\end{array}$ & $\begin{array}{l}\text { Cuaderno } \\
\text { de apuntes } \\
\text { Calculadora } \\
\text { Esferos } \\
\text { Hojas de } \\
\text { papel bond } \\
\text { Laptop }\end{array}$ & $\begin{array}{l}\text { Centrifuga. } \\
\text { Autoclave } \\
\text { Estufa. } \\
\text { Mufla } \\
\text { Equipo de } \\
\text { determinación de } \\
\text { proteína (Macro } \\
\text { Kjeldahl) } \\
\text { Balanza analítica. } \\
\text { Termómetro. } \\
\text { Refrigerador. } \\
\text { Licuadora. } \\
\text { Liofilizador } \\
\text { pH-metro } \\
\text { Refractómetro } \\
\text { Ollas } \\
\text { Moldes } \\
\text { Mesa de trabajo } \\
\text { Prensa }\end{array}$ & $\begin{array}{l}\text { Labora } \\
\text { torio de } \\
\text { bromat } \\
\text { ología. } \\
\text { Labora } \\
\text { torio de } \\
\text { Proces } \\
\text { os } \\
\text { Industr } \\
\text { iales }\end{array}$ & $\begin{array}{l}\text { Etanol al 96\% } \\
\text { Ácido sulfúrico } \\
\text { Ácido } \\
\text { clorhídrico } \\
\text { Hidróxido de } \\
\text { sodio } \\
\text { Ácido bórico } \\
\text { Ácido acético } \\
\text { Agua destilada }\end{array}$ \\
\hline
\end{tabular}

Realizado por: Elaboración propia

Fuente: Bermeo, J, 2019

Mediciones Experimentales

Las mediciones experimentales que se consideraron en esta investigación fueron: 
ISSN: 2600-5859

www.concienciadigital.org

Vol. 3, $\mathrm{N}^{\circ} 2$, p. 231-249, abril - junio, 2020

Tabla No2. Mediciones Experimentales

\begin{tabular}{|c|c|c|c|}
\hline $\begin{array}{l}\text { Características } \text { físico- } \\
\text { químicas de } \\
\text { muestra de } \\
\text { fresco }\end{array}$ & $\begin{array}{l}\text { Análisis } \\
\text { microbiológicos }\end{array}$ & $\begin{array}{l}\text { Análisis } \\
\text { sensorial }\end{array}$ & $\begin{array}{l}\text { Análisis estadístico y prueba de } \\
\text { significancia }\end{array}$ \\
\hline $\begin{array}{l}\text { Contenido de Proteínas } \\
\text { Medición de } \mathrm{pH} \text {. } \\
\text { Medición del } \\
\text { porcentaje de } \\
\text { humedad. } \\
\text { Determinación de aw. }\end{array}$ & $\begin{array}{l}\text { Enterobacteriáceas } \\
\text { Echericha coli } \\
\text { Staphylococcus } \\
\text { áureos } \\
\text { Listeria } \\
\text { monocytogenes } \\
\text { Salmonela }\end{array}$ & $\begin{array}{l}\text { Para evaluar } \\
\text { la aceptación } \\
\text { del producto } \\
\text { Aceptación o } \\
\text { rechazo } \\
\text { (Prueba de } \\
\text { preferencia } \\
\text { Pareada) }\end{array}$ & $\begin{array}{l}\text { Las pruebas de significancia que se } \\
\text { emplearon en el presente trabajo de } \\
\text { investigación se describen a } \\
\text { continuación: } \\
\text { Análisis de varianza para las } \\
\text { diferencias (ADEVA). } \\
\text { Separación de medias con la prueba } \\
\text { estadística TUKEY con nivel de } \\
\text { significancia 5\%. } \\
\text { Prueba de T-students para el producto } \\
\text { final.101 }\end{array}$ \\
\hline
\end{tabular}

Realizado por: Elaboración propia

Fuente: Bermeo, J, 2019

\section{Esquema del ADEVA}

El esquema del ADEVA que se utilizó en la presente investigación se describe a continuación:

Tabla 3: Esquema del experimento para la evaluación del queso

\begin{tabular}{lllll}
\hline & & & TOTAL \\
TRATAMIENTO & CÓDIGO REPETICIONES & T.U.E(L) & L /trat \\
\hline (Queso fresco Utilizando ficina) & $\mathrm{T} 1$ & 5 & 4 & 20 \\
(Queso fresco comercial) & $\mathrm{T} 2$ & 5 & 4 & 20 \\
Total, Lt de leche & & & $\mathbf{4 0}$ \\
\hline
\end{tabular}

T.U.E: Tamaño de la Unidad Experimental.

Realizado por: Elaboración propia

Fuente: Bermeo, J, 2019

\section{Procedimiento experimental}

En el Gráfico 1 se indica el diagrama de flujo de la elaboración del queso fresco.

\section{Elaboración del queso fresco}


Gráfico 1: Diagrama de flujo de la elaboración del queso fresco

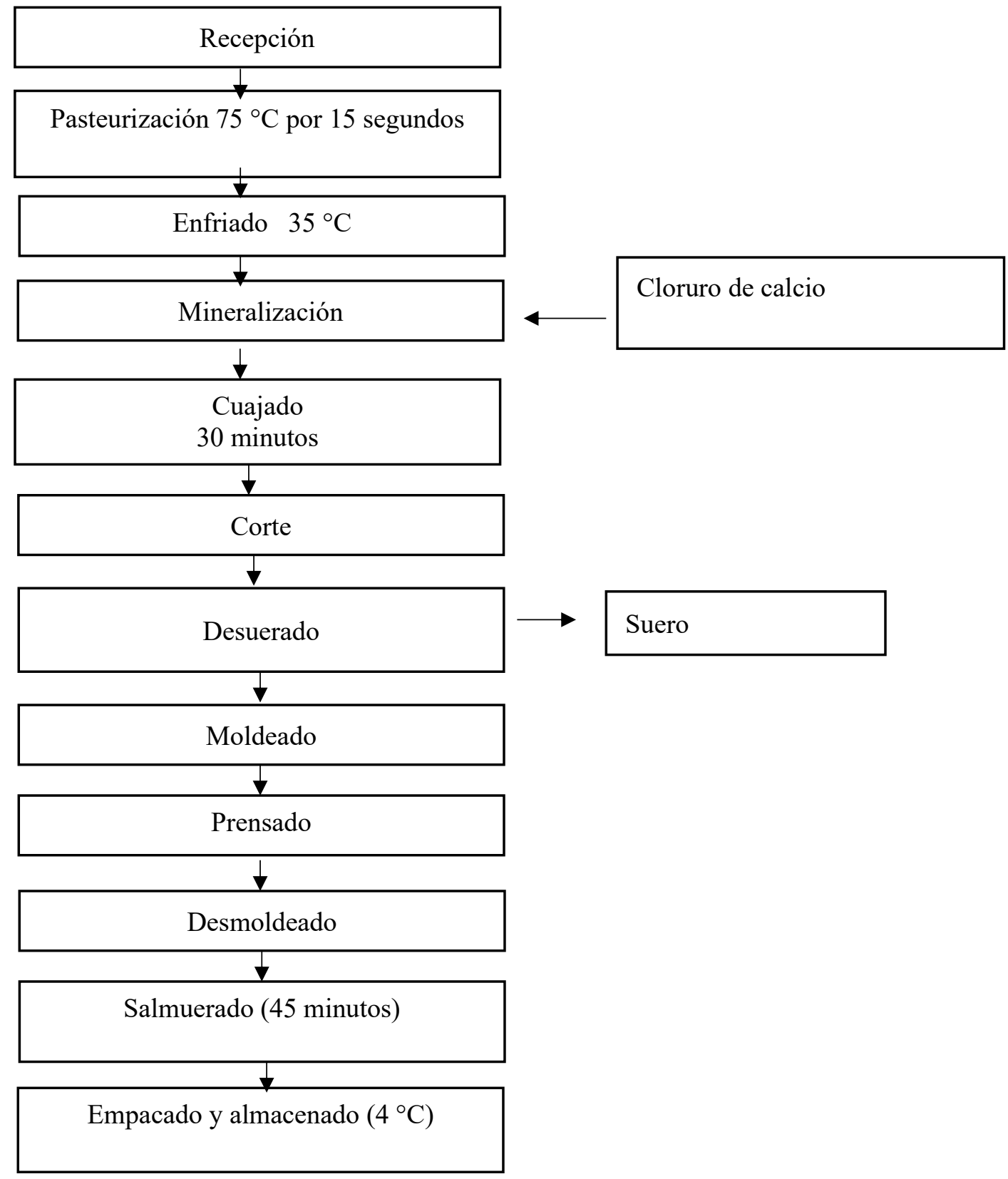

Realizado por: Elaboración propia

Fuente: Bermeo, J, 2019

\section{Recepción}

Como primer punto se realizó la limpieza y desinfección de los materiales y equipos para evitar posibles contaminaciones del producto final. Luego se procedió a la recepción de la materia prima y el control correspondiente, para asegurar que el producto final cumpla con las normas de calidad requeridas para el consumo humano, se pesó las cantidades de materia prima a utilizar en la 
elaboración del queso fresco. (Bermeo, J, 2019)

\section{Pasteurización}

Se realizó la pasteurización a $75^{\circ} \mathrm{C}$ durante 15 segundos, con la finalidad de reducir principalmente la carga microbiana patógena de la leche. (Bermeo, J, 2019)

\section{Enfriado}

Se lo realizo con agua potable hasta alcanzar una temperatura de $35^{\circ} \mathrm{C}$, temperatura requerida para continuar con la siguiente fase. (Bermeo, J, 2019)

\section{Mineralización.}

Aquí se añade el cloruro de calcio para reconstituir el calcio perdido durante la pasteurización y ayudara en la formación de la cuajada. (Bermeo, J, 2019)

\section{Cuajado}

Adición de cuajo comercial para el queso fresco comercial y la enzima ficina para el queso fresco utilizando la enzima vegetal con mejor comportamiento enzimático. (Bermeo, J, 2019)

\section{Cortado}

Se lo realiza con la ayuda de una lira realizando cortes transversales y longitudinales permitiendo un mejor desuerado. (Bermeo, J, 2019)

\section{Desuerado}

Se extrae todo el suero que se separa de la caseína. (Bermeo, J, 2019)

\section{Moldeado}

La cuajada se introduce en los moldes para darle así forma y tamaño final al queso. (Bermeo, J, 2019)

\section{Prensado}

Se lo realiza con la finalidad de expulsar la humedad o el exceso de suero logrando así mejorar la contextura del queso. (Bermeo, J, 2019)

\section{Salmuerado}

El salado contribuye en el sabor y consta de colocar el queso en la salmuera por un tiempo de 45 minutos. (Bermeo, J, 2019)

\section{Empacado y almacenado}

Se lo realizó en fundas Ziploc y fueron almacenado en refrigeración a $4{ }^{\circ} \mathrm{C}$, para su posterior análisis. (Bermeo, J, 2019)

\section{Metodología de la evaluación}

Características fisicoquímicas del medio luego de aplicado la enzima

\section{Contenido de proteína}

Para la determinación de proteína se debe pasar por tres etapas que son la digestión, destilación y titulación. (Bermeo, J, 2019)

Procedimiento:

Primer etapa digestión

- Pesar de 2 gramos de muestra.

- Pesar un pedazo de papel boom.

- Colocar la muestra eb un balón Kjeldahl. 
- Añadir 10 gramos de catalizador (CuSO4+Na2SO4).

- Adicionar $25 \mathrm{~mL}$ de ácido sulfúrico concentrado, adicionar los bordes del balón.

- Se introduce la muestra en el equipo de determinación de proteína (digestor) por un tiempo de 2 a 4 horas a una temperatura de $68^{\circ} \mathrm{C}$.

- Para dar por finalizado esta etapa se debe observar la aparición de una solución de color verde esmeralda y que no exista presencia de humo y dejar enfriar por 30 minutos. (Bermeo, J, 2019)

Etapa de destilación

- Adicionar $200 \mathrm{~mL}$ de agua destilada en el tubo digestor.

- Añadir $100 \mathrm{~mL}$ de hidróxido de sodio al $50 \%$ en un balón.

- Añadir granalla de zinc.

- Agitar y observar un color celeste.

- En un matraz Erlenmeyer adicionar $100 \mathrm{~mL}$ de ácido bórico.

- Y trasladar al equipo de destilación.

- Prender los reverberos.

- Abrir la llave de paso de agua del equipo para la destilación.

- Destilar hasta que el matraz Erlenmeyer llegue a $200 \mathrm{ml}$.

Etapa de titulación

- En el matraz de la destilación agregamos 3 gotas de indicador macro.

- Colocamos en la bureta $50 \mathrm{ml}$ de ácido clorhídrico al $0.1 \mathrm{~N}$.

- Realizamos la titulación hasta que de un color rosa pálido.

- Registramos el volumen gastado del agente titulante.

Cálculos:

(5)

Dónde:

$\mathrm{V}=\quad$ Volumen de $\mathrm{HCl}$ utilizado en la titulación.

$\mathrm{N}=\quad$ Normalidad de $\mathrm{HCl}$.

$0,014=$ Equivalente-gramo de nitrógeno.

$\mathrm{W}=\quad$ Peso de la muestra.

$\mathrm{F}=\quad$ Factor proteico $(6,38)$

\section{Características físico químicas del queso}

\section{Medición del pH}

Para el análisis de $\mathrm{pH}$ se utilizó un $\mathrm{pH}$-metro que se emplea para expresar el grado de acidez o alcalinidad de la muestra. (Bermeo, J, 2019)

Procedimiento

- Tritura la muestra

- Tamizar la muestra

- Comprobar el correcto funcionamiento del potenciómetro. 
- Determinar el pH introduciendo el electrodo en la muestra.

- Anotar los resultados.

\section{Determinación de la aw.}

Se realizo con la ayuda del equipo Lab Touch-aw que determina la actividad del agua Procedimiento. (Bermeo, J, 2019)

- Preparar una muestra representativa.

- Colocar la muestra en la capsula de medida solo hasta la mitad.

- Cerrar la capsula y colocar en el equipo.

- Esperar que el equipo termine de leer la muestra y anotar los resultados.

\section{Medición del porcentaje de humedad}

Procedimiento: (Bermeo, J, 2019)

Tarar los crisoles en la estufa durante dos horas.

Sacar los crisoles de la estufa y colocar en un desecador durante 30 minutos.

- Pesar los crisoles y anotar los resultados.

- Pesar 2 gramos de muestra.

- Colocar la muestra en los crisoles tarados.

- Colocar la muestra en la estufa a $105^{\circ} \mathrm{C}$ durante 12 horas con la ayuda de pinzas.

- Sacar los crisoles con las muestras y colocar en el desecador durante 30 minutos.

- Pesar la muestra seca de los crisoles y anotar los resultados.

Cálculos:

(6)

Donde:

$\mathrm{H}=$ Humedad en porcentaje.

$\mathrm{W} 1=$ Peso del crisol vacío.

W2 = Peso del crisol más la muestra húmeda.

W3 = Peso del crisol más la muestra seca.

\section{Análisis sensorial}

Con la finalidad de evaluar la aceptación del producto que fue elaborado utilizando la enzima con mejor comportamiento enzimático, se realizó la prueba Afectiva de preferencia pareada, a dos muestras de queso fresco, tales como queso fresco utilizando la enzima ficina (200) y muestra de queso comercial (250). La prueba consistió en elegir una muestra en base al gusto y disgusto.

Esta prueba consiste en presentar a los panelistas dos muestras del producto alimenticio a evaluar, preguntándole en el formulario sobre alguna característica que se esté evaluando del producto como: cuál de las dos muestras es más dulce, cuál de las dos muestras es insípida, cuál de las dos muestras es más acida, etc. (Bermeo, 2019, citado en LIRIA, M. 2007. p. 11-12) 
ISSN: 2600-5859

Vol. 3, N², p. 231-249, abril - junio, 2020

Las muestras se presentaron en recipientes idénticos, codificados, las mismas que fueron evaluadas por 150 panelistas no entrenados (estudiantes que hayan cursado la catedra de Análisis Sensorial) de la Facultad de Ciencias Pecuarias, ESPOCH.

\section{Análisis microbiológicos.}

Para determinar la presencia de microorganismos en la muestra de queso fresco se utilizó la norma (Bermeo, 2019, citado en NTE INEN 1528). Donde señala que los quesos frescos no madurados, ensayados de acuerdo con las normas ecuatorianas correspondientes deben cumplir con requisitos microbiológicos establecidos en la Tabla 3

Tabla 4. Requisitos microbiológicos para queso fresco no madurado.

\begin{tabular}{lllll}
\hline \multicolumn{1}{c}{ Requisitos } & N m & M & C & Método de ensayo \\
\hline Enterobacteriáceas, UFC/g & 5 & & 1 & NTE INEN 1529-13 \\
Escherichia, UFC/g & $5<10$ & 10 & 1 & AOAC 991. 14 \\
Staphylococcus aureus, UFC/g & 5 & & 1 & NTE INEN 1529-14 \\
Listeria monocytogenes $/ 25 \mathrm{~g}$ & 5 Ausencia & - & & ISO 11290-1 \\
Salmonella en $25 \mathrm{~g}$ & 5 AUSENCIA & - & 0 & NTE INEN 1529-1 \\
\hline
\end{tabular}

Realizado por: Elaboración propia

Fuente: Bermeo, 2019, citado en NTE INEN 1528

Donde:

$\mathrm{n}=$ Número de muestras a examinar.

$\mathrm{m}=$ índice máximo permisible para identificar nivel de buena calidad.

$\mathrm{M}=$ índice máximo permisible para identificar nivel aceptable de calidad.

$\mathrm{c}=$ Número de muestras permisibles con resultados entre $\mathrm{m}$ y $\mathrm{M}$.

Preparación de la muestra:

Limpiar con alcohol el empaque que contiene los quesos y abrir.

Colocar el queso sobre una superficie limpia y seca.

Realizar el cuarteamiento de la muestra.

Pesar $50 \mathrm{~g}$ de muestra y colocar en una bolsa Ziploc.

Triturar y mezclar hasta conseguir una masa homogénea.

Para la determinación de estos microorganismos se debe seguir con el siguiente procedimiento:

- Una vez adquirida las placas petrifilm se almaceno los paquetes cerrados a una temperatura de $\leq 8{ }^{\circ} \mathrm{C}\left(\leq 46^{\circ} \mathrm{F}\right)$. Las placas deben usarse antes de su fecha de caducidad.

- Preparar una dilución de la muestra; se toma 1 gr de la muestra y se agrega $9 \mathrm{ml}$ de agua peptonada como diluyente estéril.

- Homogenizar la muestra mediante los métodos usuales. 
- Colocar la placa petrifilm en una superficie plana y nivelada. Levantar la película superior en forma perpendicular a la Placa Petrifilm, colocar $1 \mathrm{ml}$ de la dilución de la muestra en el centro de la película cuadriculada inferior.

- Bajar con cuidado la película superior para evitar que atrape burbujas de aire.

- Con el lado liso hacia abajo, colocar el dispersor en la película superior sobre el inoculo, presionar suavemente el dispersor para distribuir el inoculo sobre el área circular. No girar ni deslizar el dispersor.

- Levantar el dispensador, esperar un minuto a que solidifique el gel.

- Incubar las placas caras arriba en grupos de no más de 20 piezas. A una temperatura de 35 ${ }^{\circ} \mathrm{C} \pm 1{ }^{\circ} \mathrm{C}$ por 24 horas \pm 2 horas.

- Las placas Petrifilm pueden ser contadas en un contador de colonias estándar u otro tipo de lupa con luz.

En la Tabla 5 se puede observar la temperatura y tiempo de incubación de los microorganismos.

Tabla 5. Condiciones de incubación de acuerdo a los microorganismos

\begin{tabular}{ll}
\hline Microorganismo & Condiciones de incubación \\
Enterobacteriáceas & $35^{\circ} \mathrm{C} \pm 1{ }^{\circ} \mathrm{C}$ durante 24 horas \\
Echericha coli & $35^{\circ} \mathrm{C} \pm 1{ }^{\circ} \mathrm{C}$ durante 48 horas \pm 2 horas \\
Staphylococcus áureos & $35^{\circ} \mathrm{C} \pm 1^{\circ} \mathrm{C}$ durante 24 \\
& horas \\
Listeria monocytogenes & $35^{\circ} \mathrm{C} \pm 1^{\circ} \mathrm{C}$ durante 76 horas \\
Salmonela & $35^{\circ} \mathrm{C} \pm 1^{\circ} \mathrm{C}$ durante 72 horas \\
\hline
\end{tabular}

Realizado por: Elaboración propia

Fuente: Bermeo, 2019, citado en Guía de interpretación 3M Placas Petrifilm

\section{Resultados y Discusión}

Análisis de las características físico químicas del queso fresco comercial y queso fresco utilizando ficina.

\section{Análisis de Proteína}

En el análisis del contenido de proteína en la (Tabla 3) se muestra diferencias significativas $(<0,005)$ para el queso fresco comercial y el queso fresco utilizando la ficina donde nos muestran valores de proteína de $(18,13 \%$ y 9,27 \%) respectivamente, comparando con la investigación realizada por (Bermeo, 2019, citado en Alais, 1985), (Bermeo, 2019, citado en Hekken y Farkye, 2003), (Bermeo, 2019, citado en García e Islas, 2006) señalan que el porcentaje de proteína en el queso fresco está en un rango de 17 a $21 \%$. Donde la proteína del queso fresco comercial se encuentra dentro de lo establecido sin tener afectaciones, mientras que para el queso elaborado con ficina el porcentaje de proteína difiere notoriamente esto puede deberse a lo mencionado por (Bermeo, 2019, citado en Aguirre y Castillo, 2009, p.9) donde señala que cuando existe una 
disminución en el porcentaje de proteína en el queso se debe a que la enzima vegetal no ha reaccionado por completo con la proteína debido a que no se ha realizado un proceso de purificación en la enzima.

Tabla 6: Análisis de las características físico químicas del queso (Proteína).

\begin{tabular}{lll}
\hline PROTEINA & \multicolumn{2}{c}{ Queso utilizando Queso Comercial } \\
& la enzima ficina \\
\hline Media & 9,27 & 18,13 \\
Varianza & 0,95911552 & 0,8114316 \\
Observaciones & 5 & 5 \\
Coeficiente de correlación de Pearson & 0,77680778 & \\
Diferencia hipotética de las medias & 0 & \\
Grados de libertad & 4 & \\
Estadístico t & $-31,3103971$ \\
$\mathrm{P}(\mathrm{T}<=\mathrm{t})$ una cola & $3,1004 \mathrm{E}-06$ \\
Valor crítico de t (una cola) & 2,13184678 \\
$\mathrm{P}(\mathrm{T}<=\mathrm{t})$ dos colas & $6,2008 \mathrm{E}-06$ \\
Valor crítico de t (dos colas) & 2,77644511 \\
\hline
\end{tabular}

Realizado por: Elaboración propia

Fuente: Bermeo, 2019, citado en INFOSTAT, 2019

Prob $>0,05$ : no existe diferencias estadísticas

Prob $<0,05$ : existe diferencias significativas

Prob $<0,01$ : existen diferencias altamente significativas

\section{Análisis del pH.}

Al realizar el análisis del $\mathrm{pH}$ en el queso fresco comercial y el queso fresco elaborado con ficina, como se muestra en la (Tabla 4) existen diferencias significativas $(<0,005)$ encontrándose valores de $(6,53$ y 6,74$)$ respectivamente, y que en comparación con diferentes investigaciones realizadas como los de (Bermeo, 2019, citado en Alais, 1985), (Bermeo, 2019, citado en Van Hekken y Farkye, 2003), (Bermeo, 2019, citado en García e Islas, 2006) señalan que el pH en el queso fresco va desde $(6,1$ a 6,7$)$ demostrando que la presente investigación se encuentra dentro de los rangos. Además (Bermeo, 2019, citado en Antenaza, 2015, p.55) indica que algunas de las causas del descenso en el pH se atribuyen al crecimiento de bacterias sobrevivientes a la pasteurización y/o contaminación cruzada en la elaboración y almacenamiento del mismo.

Tabla 7: Análisis de las características físico químicas del queso $(\mathrm{pH})$.

\begin{tabular}{lll}
\hline $\boldsymbol{p H}$ & $\begin{array}{l}\text { Queso utilizando la } \\
\text { enzima ficina }\end{array}$ & Queso Comercial \\
\hline Media & 6,746 & 6,534 \\
\hline
\end{tabular}




\begin{tabular}{lll}
\hline Varianza & $8 \mathrm{E}-05$ & $8 \mathrm{E}-05$ \\
Observaciones & 5 & 5 \\
Coeficiente de correlación de Pearson & $-0,0625$ & \\
Diferencia hipotética de las medias & 0 & \\
Grados de libertad & 4 & 36,3577001 \\
Estadístico t & $1,7082 \mathrm{E}-06$ \\
$\mathrm{P}(\mathrm{T}<=\mathrm{t})$ una cola & 2,13184678 \\
Valor crítico de t (una cola) & $3,4165 \mathrm{E}-06$ \\
$\mathrm{P}(\mathrm{T}<=\mathrm{t})$ dos colas & 2,77644511 \\
Valor crítico de t (dos colas) &
\end{tabular}

Realizado por: Elaboración propia

Fuente: Bermeo, 2019, citado en INFOSTAT, 2019

Prob $>0,05$ : no existe diferencias estadísticas

Prob $<0,05$ : existe diferencias significativas

\section{Análisis de aw.}

Al realizar el análisis de la aw en los quesos frescos se encontraron diferencias significativas como se puede apreciar en la (Tabla 5) dando valores de 0,79 para el queso comercial y 0,78 para el queso elaborado con ficina, encontrándose dentro de los rangos sin tener mayor afectación según lo señalado por (Bermeo, 2019, citado en Arévalo, 2014, p, 27) la aw varia en quesos frescos desde 0,70 a 1 por lo que el crecimiento de los microorganismos alcanza un máximo entre 0,9 y 1,0 después decrece rápidamente con la reducción de la aw.

Tabla 5: Análisis de las características físico químicas del queso fresco (aw).

\begin{tabular}{lll}
\hline$A w$ & $\begin{array}{l}\text { Queso utilizando la enzima Queso Comercial } \\
\text { ficina }\end{array}$ \\
\hline Media & 0,7858 & 0,7958 \\
Varianza & $5,47 \mathrm{E}-05$ & 0,0000137 \\
Observaciones & 5 & 5 \\
Coeficiente de correlación de Pearson & 0,44566229 & \\
Diferencia hipotética de las medias & 0 & \\
Grados de libertad & 4 & \\
Estadístico t & $-3,37099931$ & \\
$\mathrm{P}(\mathrm{T}<=\mathrm{t})$ una cola & 0,01400889 & \\
Valor crítico de $\mathrm{t}$ (una cola) & 2,13184678 & \\
$\mathrm{P}(\mathrm{T}<=\mathrm{t})$ dos colas & 0,02801779 & \\
Valor crítico de t (dos colas) & 2,77644511 & \\
\hline
\end{tabular}

Realizado por: Elaboración propia

Fuente: Bermeo, 2019, citado en INFOSTAT, 2019 
Prob >0,05: no existe diferencias estadísticas

Prob $<0,05$ : existe diferencias significativas

Prob $<0,01$ : existen diferencias altamente significativas

\section{Análisis del porcentaje de humedad}

Al realizar el análisis del porcentaje de humedad en el queso fresco comercial y el queso fresco utilizando ficina no se encuentran diferencias significativas como se muestra en la (Tabla 6) obteniendo valores de $(60,82$ y 60,54$)$ mismos que se encuentran dentro de la Norma Técnica Ecuatoriana (INEN 63) en el que el queso fresco no debe tener un porcentaje de humedad superior al $80 \%$ donde se encuentran dentro del rangos establecidos sin tener mayor afectación.

Tabla 6: Análisis de las características físico químicas del queso del porcentaje de humedad.

\begin{tabular}{lll}
\hline$\%$ HUMEDAD & Queso utilizando la enzima ficina & Queso Comercial \\
\hline Media & 60,5401111 & 60,8221557 \\
Varianza & 13,9863871 & 0,61372078 \\
Observaciones & 5 & 5 \\
Coeficiente de correlación de Pearson & 0,28281102 & \\
Diferencia hipotética de las medias & 0 & \\
Grados de libertad & 4 & \\
Estadístico t & $-0,1753017$ & \\
$\mathrm{P}(\mathrm{T}<=\mathrm{t})$ una cola & 0,43467937 & \\
Valor crítico de $\mathrm{t}$ (una cola) & 2,13184678 & \\
$\mathrm{P}(\mathrm{T}<=\mathrm{t})$ dos colas & 0,86935873 & \\
Valor crítico de $\mathrm{t}$ (dos colas) & 2,77644511 & \\
\hline
\end{tabular}

Realizado por: Elaboración propia

Fuente: Bermeo, 2019, citado en INFOSTAT, 2019

Prob $>0,05$ : no existe diferencias estadísticas

Prob $<0,05$ : existe diferencias significativas

Prob $<0,01$ : existen diferencias altamente significativas

\section{Análisis sensorial}

Al realizar el análisis de preferencia pareada para los dos tipos de quesos, tanto el queso fresco comercial como el elaborado utilizando la mejor enzima, se pudo obtener como resultado que la mayor aceptación la obtiene el queso comercial con el 100\% de preferencia, como se puede observar en el Grafico 2. 
Gráfico 2. Análisis sensorial de preferencia: muestra 200 (queso comercial), muestra 250 (queso fresco utilizando la enzima ficina.

\section{CUAL MUESTRA PREFIERE?}

-MUESTRA 200 mUESTRA 250

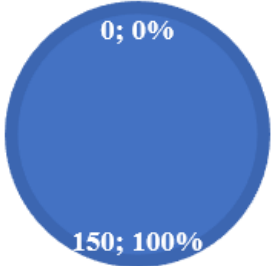

Realizado por: Elaboración propia

Fuente: Bermeo, J, 2019

\section{Análisis microbiológico.}

Al analizar la muestra de queso fresco comercial y queso fresco utilizando la mejor enzima, se observa en la Tabla 7 y Tabla 8, no hubo existencia de Enterobacteriáceas, Echerichia coli, Staphylococcus aureus, Listeria monocytogenes, Salmonela, encontrándose dentro de la Norma Técnica Ecuatoriana INEN 1528 en donde señala el índice máximo permisible para identificar el nivel aceptable de calidad.

Tabla 7: Análisis microbiológico de una muestra de queso fresco comercial

\begin{tabular}{cccccc}
\hline & & & \multicolumn{2}{c}{ Microorganismos } & \\
\cline { 3 - 4 } Repeticiones & Enterobacteriáceas & Echericha coli & Staphylococcus aureus & Listeria monocytogenes & Salmonela \\
\hline 1 & 0 & 0 & 0 & Ausencia & Ausencia \\
2 & 0 & 0 & 0 & Ausencia & Ausencia \\
3 & 0 & 0 & 0 & Ausencia & Ausencia \\
4 & 0 & 0 & 0 & Ausencia & Ausencia \\
5 & 0 & 0 & 0 & Ausencia & Ausencia \\
\hline
\end{tabular}

Realizado por: Elaboración propia

Fuente: Bermeo, J, 2019

Tabla 8: Análisis microbiológico de una muestra de queso fresco utilizando la enzima ficina

\begin{tabular}{llllll}
\hline & & \multicolumn{3}{c}{ Microorganismos } & \\
\cline { 3 - 4 } Repeticiones & Enterobacteriáceas & Echericha coli & Staphylococcus áureos & Listeria monocytogenes Salmonela \\
\hline 1 & 0 & 0 & 0 & Ausencia & Ausencia \\
2 & 0 & 0 & 0 & Ausencia & Ausencia \\
3 & 0 & 0 & 0 & Ausencia & Ausencia \\
4 & 0 & 0 & 0 & Ausencia & Ausencia \\
5 & 0 & 0 & 0 & Ausencia & Ausencia \\
\hline
\end{tabular}

Realizado por: Elaboración propia

Fuente: Bermeo, J, 2019 


\section{Conclusiones.}

- Se analizaron los resultados físico-químicos obtenidos mediante la utilización de la fícina en la elaboración de una muestra de queso fresco en \% de humedad fue de 60,54, aw 0,78 $\%, 9,27 \%$ de proteína y $\mathrm{pH} 6,74$, valores que en comparación con un queso fresco comercial no difieren cuantitativamente a excepto de la proteína con una diferencia de 8,86 $\%$ entre ambos, en cuanto a la determinación de $\%$ de humedad fue de 60,82 , para la aw se obtuvo un resultado de 0,79 , y finalmente un $\mathrm{pH}$ de 6,53 .

- En el análisis sensorial el $100 \%$ de catadores prefirió el queso fresco comercial.

- En los análisis microbiológicos realizados a muestras de queso fresco comercial y queso fresco mediante la adición de la enzima denominada ficina, no se reportó presencia de microorganismos como por ejemplo: Enterobacteriáceas, Escherichia coli, y Staphylococcus aureus, Listeria monocytogenes y Salmonella, encontrándose de ésta manera dentro de los parámetros establecidos en la Norma Técnica Ecuatoriana INEN 1528 que básicamente implica y establece los requisitos para el queso fresco no madurado, incluido el queso fresco, destinado al consumo directo o a posterior elaboración, en donde señala que el análisis microbiológico correspondiente, los quesos frescos no madurados deben dar ausencia de microorganismos patógenos, de sus metabolitos y toxinas.

\section{Referencias bibliográficas.}

Acosta, R., 2011. Estudio de la variación de la actividad enzimática proteolítica del latex del babaco (Vasconcellea heilbornii cv babaco) en función a la edad del fruto http://bibdigital.epn.edu.ec/bitstream/15000/3924/1/CD-3656.pdf

Alais, C. (2000). Ciencia de la leche: principios de técnica lechera. https://books.google.es/books?hl=es\&lr=\&id=bW_ULacGBZMC\&oi=fnd\&pg=PR5\&dq $=$ Alais + principio + de + técnicas + lecheras\&ots $=$ QN_s8_40dy\&sig $=4 \mathrm{sDZdQPGC} 8 \mathrm{kdjWr} 4 \mathrm{u}$ $\mathrm{yB} 3 \mathrm{tdprxe} 0 \# \mathrm{v}=$ onepage $\& \mathrm{q}=$ Alais principio de técnicas lecheras $\& \mathrm{f}=\mathrm{false}$

Aguirre, E., Castillo, P. 2009. Extracción y estudio comparativo de las enzimas proteolíticas del fruto toronche (Carica-Stipulata) y de la papaya (Carica-Papaya) y su aplicación en la industria alimentaria. https://www.dspace.espol.edu.ec/bitstream/123456789/7532/1/Extraccion\%20y\%20Estud io\%20Comparativo\%20de\%20las\%20Enzimas\%20Proteol\%C3\%ADticas.pdf

Carrera, J. E. (n.d.). Producción y Aplicación de Enzimas Industriales Production And Application Of Industrial Enzymes.

Gallardo, L., Sánchez, A., Montalvo, C., \& Alonso, A. (2008). Extracción de Bromelina A Partir de Residuos de Piña. In Ciencia y Tecnología de Alimentos (Vol. 18). 
ISSN: 2600-5859

www.concienciadigital.org

Vol. 3, N², p. 231-249, abril - junio, 2020

Juca Villalta, D. N. (2015). Universidad del Azuay Facultad de Ciencia y Tecnología Escuela de Ingeniería en Alimentos. Universidad del Azuay

Maigua, A. 2017. Evaluación de enzimas coagulantes del estómago de conejo en la elaboración de queso fresco.

ESPOCH. http://dspace.espoch.edu.ec/bitstream/123456789/7094/1/17T1464.pdf

Mallma, A., 2017. Efecto del cuajo vegetal latex de higuera (Ficus carica Linnaeus) en la elaboración del queso fresco. http://repositorio.unajma.edu.pe/bitstream/handle/123456789/250/Aydee_Tesis_bachiller 2017.pdf? sequence $=3$ \&isAllowed $=y$

Nolivos, M., 2011. Uso de Cuajo Vegetal (Leche de Higo Verde-Ficus Carica Linnaeus) Para la Elaboración de Queso Fresco. http://repositorio.uta.edu.ec/bitstream/123456789/3258/1/PAL262.pdf

Pezo, K. D., 2018. Determinación de la Actividad Proteolítica de la Enzima Bromelina Obtenida de la Corteza de Ananas Comosus, Sobre Extracto Acuoso de Carne http://repositorio.ug.edu.ec/bitstream/redug/36132/1/BCIEQ-T 0341\%20Del\%20Pezo\%20Sol\%C3\%ADs\%20Katherin\%20Abigail.pdf

Pilar, Y., 2017. Extracción de proteasas de Ulex Europaeus L. y su potencial utilización como sustituto de cuajo..

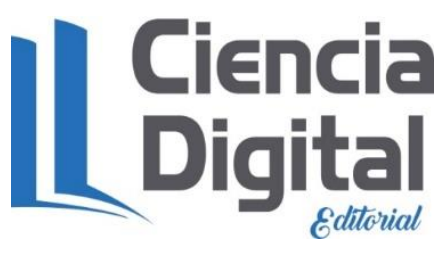




\section{PARA CITAR EL ARTÍCULO INDEXADO.}

Bermeo Berrones, J. G., Salgado Tello, I. P., Flores Mancheno, C. I., \& Sánchez Herrera, T. E. (2020). Evaluación físico-química, microbiológica y sensorial del queso fresco utilizando ficina como biocatalizador. $\quad$ ConcienciaDigital, $\quad 3(2.1), \quad$ 231-249. https://doi.org/10.33262/concienciadigital.v3i2.1.1238

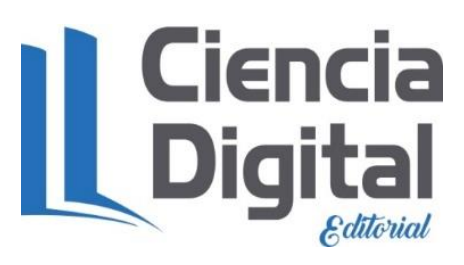

El artículo que se publica es de exclusiva responsabilidad de los autores y no necesariamente reflejan el pensamiento de la Revista Conciencia Digital.

El artículo queda en propiedad de la revista y, por tanto, su publicación parcial y/o total en otro medio tiene que ser autorizado por el director de la Revista Conciencia Digital.
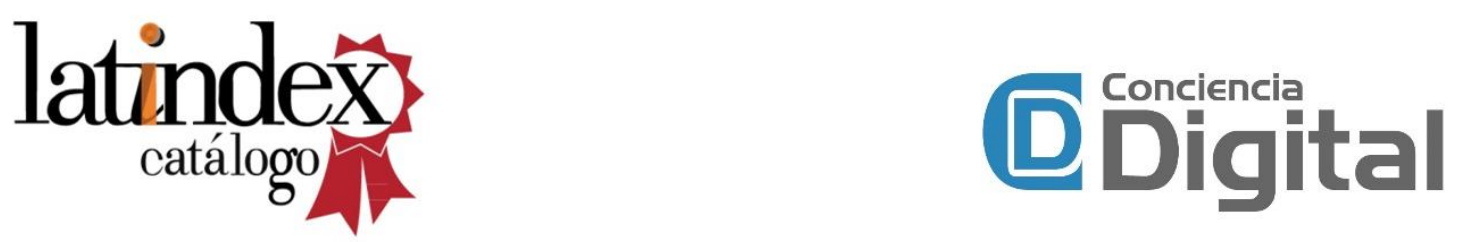